\title{
OS USOS E COSTUMES DA SOCIEDADE NAS CRÔNICAS DE GRACILIANO RAMOS EM CULTURA POLÍTICA: REVISTA MENSAL DE ESTUDOS BRASILEIROS
}

\section{THE HABITS AND CUSTOMS OF SOCIETY IN THE CHRONICLES OF GRACILIANO RAMOS IN CULTURA POLITICA: MONTHLY MAGAZINE OF BRAZILIAN STUDIES}

\author{
Patrícia Aparecida Gonçalves de Faria ${ }^{1}$
}

Receibido em: 19 jul. 2019.

Aceito em: 22 dez. 2019.

DOI 10.26512/aguaviva.v5i1.26242

RESUMO: Graciliano Ramos (1892-1953) colaborou durante os anos de 1941 a 1944, com Cultura Política: revista mensal de estudos brasileiros (1941-1944), principal publicação do Departamento de Imprensa e Propaganda (DIP), controlado pelo Estado Novo. Assim, considerando o percurso intelectual e literário do autor de Vidas Secas, este trabalho pretende levantar as características da revista e suas estratégias para manter em seu rol de colaboradores figuras importantes, como Graciliano Ramos e, ainda, analisar as publicações do autor para o periódico, que abordaram os usos e costumes da sociedade verificando as estratégias de escrita utilizadas pelo escritor para publicar suas crônicas em Cultura Política.

Palavras-chave: Graciliano Ramos. Cultura Política. Crônicas.

ABSTRACT: Graciliano Ramos (1892-1953) collaborated from the years of 1941 to 1944 in Cultura Politica: monthly magazine of Brazilian studies (1941-1944), the main publication of the Press and Advertising Department, controlled by the Estado Novo. Thus, considering the intellectual and literary path of the writer of Vidas Secas, this research aims to study the characteristics of the magazine and its strategies to maintain a group of important people, such as Graciliano Ramos and, besides, analyze the author's publications on the magazine that dealt with the habits and customs of society in order to verify the strategies of writing used by the writer to publish his chronicles in Cultura Política.

Keywords: Graciliano Ramos. Cultura Política. Fait divers.

\footnotetext{
${ }^{1}$ Doutora em Letras pela Universidade Estadual Paulista Júlio de Mesquita Filho - Campus de São José do Rio Preto. Mestre em Literatura e Vida Social pela Universidade Estadual Paulista Júlio de Mesquita Filho - Campus de Assis. Possui graduação em Letras/Italiano pela Universidade Estadual Paulista Júlio de Mesquita Filho. Email: patricia_faria09@yahoo.com.br
} 


\section{Os escritos de Graciliano Ramos em Cultura Política: revista mensal de estudos brasileiros}

Com o intuito de evitar confrontos diretos com os intelectuais que não apoiavam o regime do Estado Novo, o governo Vargas procurou contornar os posicionamentos desses escritores objetivando impedir uma oposição aberta, mesmo vigorando a censura, fortemente exercida pelo DIP. Para tal intento, criou Cultura Política: revista mensal de estudos brasileiros, que circulou de março de 1941 a outubro de 1945, com o intuito de promover e divulgar os feitos governamentais e culturais do país.

No decorrer de sua existência foram publicados cinquenta números com uma tiragem mensal de aproximadamente 3.000 exemplares que contavam com aproximadamente 300 páginas medindo 16 x 22,5 cm. A exceção ficou por conta dos três últimos números que, com o fim da Agência Nacional, reduziram as suas páginas para cento e poucas numa medida de 13,50 x 18,50 cm; todas as publicações da revista foram realizadas por Fernando Chinaglia S/A.

Desde a sua fundação em março de 1941 até a sua extinção em outubro de 1945, a revista foi dirigida por Almir Bonfim de Andrade a convite de Lourival Fontes, diretor do DIP. Vale ainda destacar que no sumário, na maioria das publicações, antes da enumeração das seções, havia um artigo escrito pelo diretor da revista que assinava no final dos escritos como A. de A. Em seguida, no mesmo sumário, apareciam as seis seções fixas enumeradas que perdurariam até agosto de 1942, na edição de número 18. Entretanto, alguns conflitos no DIP e o início da participação do Brasil na Segunda Guerra Mundial fez com que seções fossem agrupadas ou extintas, dando lugar a novas seções.

A principal finalidade da revista era, de fato, estudar, determinar e esclarecer as transformações sócio-econômicas que aconteciam no país. Ela, ainda, relatava as realizações e os feitos governamentais, e funcionava como um veículo de divulgação das publicações e feitos realizados por Getúlio Vargas e o Estado Novo. Assim, Peterle (2010, p. 74) afirma que “Cultura Política, uma das publicações promovidas pelo Estado Novo, ligada diretamente ao Departamento de Imprensa e Propaganda (DIP), apresentava como primeiro objetivo a divulgação das mudanças do país e as iniciativas governamentais".

Desta forma, devido às suas qualidades editoriais, a sua extensão e ao grande investimento financeiro, conseguiu fazer jus à sua missão, uma vez que estampou com coerência em suas páginas particularidades culturais de várias áreas, reunindo colaboradores de grande capacidade intelectual.

Coerentemente, para fundamentar o seu propósito de atuar em diversas áreas da cultura 
e da política, a revista precisou recrutar inúmeros colaboradores. A última seção, intitulada "Brasil social, intelectual e artístico", contou com figuras renomadas que escreviam sobre temas relacionados à arte e à cultura nas subseções dessa última seção. Exemplos notáveis são: Marques Rebelo em "Quadros e Costumes do Centro e do Sul”, Graciliano Ramos em "Quadros e Costumes do Nordeste", Lúcio Cardoso em "Cinema”, Wilson Louzada em "Literatura de Ficção", Guerreiro Ramos em "Literatura Latino-americana", entre outros.

Inclusive, muitos deles, antes de escreverem para Cultura Política, estiveram do lado oposto do regime implantado por Vargas, mas no momento da publicação do periódico acabaram emprestando a sua pena com o intuito de registrar colaborações que pudessem firmar as mudanças sociais, políticas e culturais pela qual passava o país após o governo Vargas.

No Brasil, um caso muito particular permeou a atividade de muitos artistas, como Candido Portinari, Graciliano Ramos, Carlos Drummond de Andrade e José Lins do Rego, entre outros, que estiveram ao mesmo tempo, dentro e fora da política governamental, pois apesar de estarem ligados ao governo pelas funções empregatícias que exerciam, não deixavam de manter os seus posicionamentos, ideologias e olhar crítico.

Grande parte destes intelectuais, literatos, arquitetos, músicos e pintores, entre outros, foram reunidos durante o ministério de Gustavo Capanema, durante os anos de 1934 e 1945, nomeados como a constelação de Capanema. Portanto, estes "funcionários do estado" viviam sob a ótica de um duplo viés, pois precisavam exercer seu trabalho junto ao Estado por motivos financeiros, todavia, sem deixar-se alienar perante as práticas políticas adotadas. Além destes intelectuais existiam, ainda, outros grupos que preferiam adotar uma única perspectiva, ou seja, se rendiam aos encantos do governo e emprestavam o seu trabalho artístico em prol da propagação dos propósitos governamentais.

Antonio Candido no prefácio da obra de Ségio Miceli Intelectuais à brasileira analisa essa relação peculiar entre os intelectuais e o estado durante o governo Vargas.

Mas o fato é que no processo estão envolvidos os homens, com a sua carne e a sua alma, de modo que conviria acentuar mais que um Carlos Drummond de Andrade "serviu" o Estado Novo como funcionário que já era antes dele, mas não alienou por isso a menor parcela da sua dignidade ou autonomia mental. Tanto assim que as suas idéias contrárias eram patentes e foi como membro do gabinete do ministro Capanema que publicou os versos políticos revolucionários de Sentimento do mundo e compôs os de Rosa do povo. Já um Cassiano Ricardo se enquadrou ideologicamente e apoiou pela palavra e pela 
ação, porque o regime correspondia à noção de democracia autoritária e nacionalista (CANDIDO, 2001, p. 74).

Assim como Carlos Drummond de Andrade serviu o Estado, podemos afirmar que o escritor de Vidas Secas também conseguiu manter o seu equilíbrio como escritor, funcionário do estado e colaborador de Cultura Política, não se rendendo em nenhum momento em suas obras à ideologia vigente, ao contrário, colaborou em um periódico dipiano sem precisar citar abertamente o nome de Getúlio Vargas, como muitos dos colaboradores da revista.

A colaboração de Graciliano Ramos em Cultura Política se deu entre os anos de 1941 a 1944, representando a mais duradoura de suas contribuições em um único periódico. De sua autoria foram publicadas 25 crônicas, sendo 21 nos anos de 1941 e 1942, duas em 1943 e duas em 1944. Deve-se esclarecer que as primeiras 18 foram estampadas nos 18 números iniciais da revista, na seção intitulada "Quadros e costumes do Nordeste"; quatro se encontram em "Quadros e costumes regionais"; duas estão em "Quadros regionais" e apenas uma na seção "Literatura".

As crônicas publicadas por Graciliano Ramos na seção Quadros e Costumes do Nordeste não apresentavam títulos, mas apenas o número da crônica e o nome do seu autor. Portanto, em Quadros e Costumes do Nordeste foram publicadas as seguintes crônicas: I (1941), II (1941), III (1941), IV (1941), V (1941), VI (1941), VII (1941), VIII (1941), IX (1941), X (1941), XI (1942), XII (1942), XIII (1942), XIV (1942), XV (1942), XVI (1942), XVII (1942), XVIII (1942).

$\mathrm{Na}$ seção Quadros e costumes regionais foram estampadas quatro crônicas, que receberam os seguintes títulos para a publicação na revista: A decadência de um senhor de engenho (1942), Recordações duma indústria morta (1942), Uma visita inconveniente (1942) e Está aberta a sessão do júri (1943).

Na seção Quadros regionais, Graciliano Ramos colaborou com duas crônicas, intituladas como Um homem notável (1943) e A viúva Lacerda (1944). E, por fim, na seção Literatura, publicou apenas a crônica Booker Washington (1944).

Anos mais tarde, 24 das 25 crônicas foram reunidas nas obras póstumas Viventes das Alagoas (1962) e Linhas Tortas (1962), sendo que 22 se encontram em Viventes das Alagoas e apenas duas crônicas A viúva Lacerda e Booker Washington em Linhas Tortas, ambas edições publicadas pela editora Martins. A crônica Uma visita inconveniente, por sua vez, permaneceu inédita em livros até 2012 quando o estudioso Thiago Mio Salla a publicou em Garranchos: textos inéditos de Graciliano Ramos 
As publicações póstumas de Linhas Tortas e Viventes das Alagoas foram editadas pela esposa Heloísa Ramos, pelo filho Ricardo Ramos e pelo seu genro James Amado. Portanto, as crônicas que pertenciam à seção "Quadros e Costumes do Nordeste” foram todas publicadas em Viventes das Alagoas e receberam os seguintes títulos:

- "Carnaval" - originalmente "Quadros e costumes do Nordeste I" (ano 1, n.1, mar. 1941);

- “D. Maria Amália" - originalmente "Quadros e costumes do Nordeste II” (ano 1, n.2, abr. 1941);

- "O moço da farmácia" - originalmente "Quadros e costumes do Nordeste III" (ano 1, n.3, maio 1941);

- "Casamento" - originalmente "Quadros e costumes do Nordeste IV" (ano 1, n. 4, jun. 1941);

- "Ciríaco" - originalmente "Quadros e costumes do Nordeste V” (ano 1, n. 5, jul. 1941);

- "Habitação" - originalmente "Quadros e costumes do Nordeste VI" (ano 1, n. 6, ago. 1941);

- "Teatro I" - originalmente "Quadros e costumes do Nordeste VII" (ano 1, n. 7, set. 1941);

- "Teatro II" - originalmente "Quadros e costumes do Nordeste VIII" (ano 1, n. 8, out. 1941);

- "Bagunça" - originalmente "Quadros e costumes do Nordeste IX" (ano 1, n. 9, nov. 1941);

- "D. Maria" - originalmente "Quadros e costumes do Nordeste X" (ano 1, n. 10, dez. 1941);

- "Libório" - originalmente "Quadros e costumes do Nordeste XI" (ano 2, n. 11, jan. 1942);

- "Desafio" - originalmente "Quadros e costumes do Nordeste XII" (ano 2, n. 12, fev. 1942);

- "Funcionário Independente" - originalmente "Quadros e costumes do Nordeste XIII" (ano 2, n. 13, marc. 1942);

- "Um antepassado" - originalmente "Quadros e costumes do Nordeste XIV" (ano 2, n. 14, abr. 1942); 
- "Um homem de Letras" - originalmente "Quadros e costumes do Nordeste XV" (ano 2, n. 15, maio. 1942);

- "Um gramático" - originalmente "Quadros e costumes do Nordeste XVI" (ano 2, n. 16, jun. 1942);

- "Dr. Pelado" - originalmente "Quadros e costumes do Nordeste XVII" (ano 2, n. 17, jul. 1942);

- “Transação de Cigano" - originalmente "Quadros e costumes do Nordeste XVIII" (ano 2, n. 18, ago. 1942).

Conforme já citado, após a publicação da crônica XVIII, as próximas crônicas passaram a ser intituladas para a revista. Sendo assim, aparecem desta forma:

- "Quadros e costumes regionais", intitulada "A decadência de um senhor de engenho" (ano 2, n. 19, set. 1942);

- "Quadros e costumes regionais", intitulada "Recordações duma indústria morta" (ano 2, n. 20, out. 1942);

- "Quadros e costumes regionais", intitulada "Uma visita inconveniente" (ano 2, n. 22, set. 1942);

- "Quadros e costumes regionais", intitulada "Está aberta a sessão do júri” (ano 3, n. 25, mar. 1943);

Com o fim da seção Quadros e Costumes Regionais, Graciliano Ramos publicou apenas duas crônicas na seção Quadros regionais. Apenas uma destas crônicas foi publicada em Viventes das Alagoas.

- “Quadros regionais", intitulada "Um homem notável” (ano 3, n. 27, maio. 1943); A outra crônica publicada na seção "Quadros regionais” está presente na obra Linhas Tortas:

- “Quadros regionais” intitulada “ A viúva Lacerda” ( ano 4, n. 42, jul. 1944);

E finalmente, na seção "Literatura”, Graciliano colaborou com a sua última crônica em Cultura Política, que também está publicada em Linhas Tortas.

- “Literatura" intitulada "Booker Washington" (ano 4, n. 43, jul. 1944);

Ao analisar as crônicas publicadas em Cultura Política percebe-se que o autor utilizou estratégias para manter seus escritos equilibrando os seus posicionamentos críticos com as ideologias do periódico. Verifica-se, ainda, que Graciliano Ramos escreveu suas crônicas 
norteado sobre as seguintes temáticas: o uso e os costumes da sociedade, a política e a linguagem, as relações econômicas e a vida literária do homem nordestino. Neste artigo, a temática mais extensa de suas publicações será o objeto de estudo: o uso e os costumes da sociedade.

\section{Usos e costumes nas crônicas de Graciliano Ramos em Cultura Política.}

Na publicação de estreia de Cultura Política: revista mensal de estudos brasileiros, volume 1, número 1 de março de 1941, o editor do periódico teceu algumas palavras sobre Graciliano Ramos e a missão que o escritor assumiria ao escrever sobre o nordeste brasileiro e a sua cultura. Além da apresentação do autor como cronista responsável pela seção "Quadros e Costumes do Nordeste", ainda descreveu os aspetos que seriam abordados na crônica inaugural: o Carnaval nas pequenas cidades do interior nordestino.

\footnotetext{
Escritor e romancista consagrado entre os melhores do Brasil de hoje, tendo enriquecido a nossa literatura de ficção com obras fortes e cheias de personalidade, como São Bernardo, Angustia, Vidas Secas, Caetés, e com numerosos contos que se publicam incessantemente nos grandes jornais da capital da República e dos Estados - o autor desta crônica tomou o seu encargo fixar quadros e costumes da região do Brasil onde nasceu e viveu mais de trinta anos: o nordeste.

Neste número inaugural, ele nos dá um flagrante da grande festa popular - o Carnaval - tal como decorre nas cidadelas do interior nordestino. É um pequeno pedaço desse Brasil que ainda foge ao ímpeto renovador da civilização litorânea, desse Brasil tão diferente e tão grande (ANDRADE, 1941, p. 236).
}

Antes de tudo, devemos destacar que a revista utilizou notas do editor com o intuito de conduzir a leitura e a interpretação dos leitores do periódico. Portanto, na primeira parte da nota do editor, os elogios grandiosos a Graciliano Ramos não ocorreram por acaso, pois concomitantemente, almejavam valorizar os escritos do autor e mostrar a todos que a figura ilustre, que outrora não se adaptava aos moldes do Estado Novo, agora emoldurara as suas publicações numa seção fixa "Quadros e costumes do nordeste". Noutras palavras, a contratação de Graciliano como colaborador fixo de Cultura Política aumentava o prestígio do periódico e valorizava o discurso estatal, pois contava com um escritor talentoso e reconhecido que, apesar disso, anos antes fora preso por ter sido considerado com um oposicionista aos 
ideais implantados pelo governo Vargas, mas que no momento da publicação estava disposto a colaborar com a revista Cultura Política.

$\mathrm{Na}$ segunda parte desta mesma nota introdutória, ainda tentando dirigir a leitura, a nota do editor enfatizou que os escritos de Graciliano iriam "fixar" e "flagrar" um "pequeno pedaço" do Brasil, um lugar distante que foi presenciado e vivido pelo autor por mais de trinta anos, ou seja, a nota do editor, mais uma vez, pretendeu "desficcionalizar" e aproximar da realidade os escritos de Graciliano Ramos.

A revista utilizando desta estratégia estampou a crônica inaugural de Graciliano Ramos, que retratou a sociedade e a cultura de uma pequena cidade nordestina de cinco mil habitantes. O tema central girava em torno da festa popular, o Carnaval e revelava os costumes de um povoado nordestino apegado às tradições locais sem a mínima vontade de se abrir para o novo e para novas formas de transformações sociais e econômicas. Assim, Graciliano Ramos (1941, p. 237) na seção Quadros e costumes do nordeste, na crônica I afirma: “A cidade, tradicionalista, acomoda-se aos hábitos modernos. Acomoda-se, pois não. [...]. Acomoda-se, devagar. Nada de choques, perturbações".

Por meio de alguns personagens ${ }^{2}$, o cronista, nos leva a refletir sobre os costumes tradicionalistas que estão distantes da modernidade, como a filha do telegrafista, moça beata criada na roça que segundo os habitantes locais se envolveu de maneira "indecente" durante o carnaval com o moço da farmácia, causando falatórios, inclusive da prefeita que tinha aversão a qualquer comportamento que fugisse dos moldes da cidadezinha nordestina: "A prefeita se aborrece também. Aquela agarração da menina do telegrafista com o ajudante da farmácia é um escândalo. A sonsa, que vive na igreja, confessando-se, comungando, perde os estribos e dá amostra péssima da localidade" (RAMOS, 1941, p. 237).

Como em Vidas Secas, aqui algumas personagens se animalizam quando perdem o controle da situação e da convenção imposta pela sociedade, como aconteceu com a filha do telegrafista e o moço da farmácia.

\footnotetext{
${ }^{2}$ Segundo Afrânio Coutinho, a crônica enquanto gênero literário se consolida e se constitui com outros gêneros. Para o crítico, a crônica brasileira se distende em cinco categorias tipológicas, de acordo com traços característicos do estilo adotado, podendo ser crônica narrativa, crônica metafísica, crônica poema-em-prosa, crônica-comentário e crônica-informação. Podemos perceber que Graciliano em suas crônicas para Cultura Política, em muitos momentos, adotou o estilo da crônica narrativa, pois coloca como eixo central uma história, com personagens, narrada em primeira pessoa ou terceira pessoa, o que aproxima suas crônicas do conto. Em algumas crônicas, percebemos a presença simultânea de características da crônica narrativa e da crônica comentário em há, na maioria das vezes, a ironia.
} 
Os humanos se animalizam toda vez que perdem o controle do real, mera ordem cosmética. A filha do telegrafista, beata, seduzida pelo moço da farmácia, perde os estribos. Assim, a transgressão abre o hiato entre norma e desvio, que pode interpretar-se, no caso, como ironia racionalizadora de uma situação vivida pelo amor (ANTELO, 1984, p. 29).

Portanto, foi com ironia que o cronista mostrou a acomodação do sertanejo, aos antigos carnavais presos ao passado, às transgressões, às regras impostas e aos costumes tradicionalistas que traziam tranquilidade para a população local de cinco mil habitantes: "Quando o cronista ironiza que a cidade se acomoda, sem nada de choques nem perturbações, aos novos hábitos modernos, mostrou que, de fato, a cidade continua presa à convenção e ao tradicionalismo" (ANTELO, 1984, p. 29).

Desta forma, encontramos nos relatos de Graciliano Ramos (1941, p. 236) na crônica inaugural a seguinte informação sobre o uso e costumes do espaço, uma vez que afirma: "O lugar é morigerado. Os homens nascem oportunamente, morrem oportunamente. E entre essas ocorrências comportam-se direito, mais ou menos direito, e examinam as vidas alheias, achando sempre nelas motivo para desagrado, o que muito influi na purificação do ambiente".

Na crônica VII, intitulada em Viventes das Alagoas como "Teatro I", não há nota do editor e o cenário não é mais a pequena cidadezinha, e sim a capital. Contudo, percebemos semelhanças entre os costumes e a cultura, pois em ambos cenários os homens têm o seu destino traçado pela repetição dos fatos, a conversa rotineira e a observação da vida como forma de entretenimento.

À tardinha as calçadas estreitas se estendiam de cadeiras, os vizinhos
palestravam algumas horas como se estivessem num salão, indiferentes aos
direitos do transeunte raro, que descia degraus e pisunhava entre barrocas e
pontas de pedra. Finda a conversa, recolhiam-se os moveis, fechavam-se as
portas e a cidadezinha repousava, ordeira e deserta, à luz de lâmpadas miúdas
(RAMOS, 1941, p. 263).

Podemos perceber que o espaço é visto com ironia tanto na crônica VII como na I. Observamos, ainda, ao analisar a crônica I que não há uma data que especifique quando os fatos ocorreram. No entanto, estas informações estão evidentes pelo fato do cronista utilizar o 
presente histórico $^{3}$, dando a entender que as passagens aconteceram antes de 1930. Logo, quando situou os acontecimentos antes de $1930^{4}$ e chamou a sociedade de tradicionalista e apegada ao passado, o cronista se adaptou com a proposta da revista, cujo objetivo era "definir" e "esclarecer" os novos rumos das transformações sociais e políticas do país após a revolução de 1930.

A crônica IV estampada no número quatro da revista Cultura Política trouxe aos leitores, mais uma vez, o acomodamento tradicionalista presente no interior nordestino. Desta vez, foi retratado o costume matrimonial da região, considerado por muitos sertanejos um processo de dignificação e aceitação perante a sociedade. O sertanejo, tendo consciência de que o casamento civil e religioso exigem disponibilidade de tempo e recursos, acabou adotando caminhos menos tortuosos até chegar ao enlace, uma vez que não possui propriedades para serem divididas entre as partes interessadas.

Nesta crônica observamos a dualidade de uma sociedade dividida entre proprietários e homens sem posse. Para os proprietários, a regra e o preceito do casamento perante o padre e o bispo significava a dignificação, enquanto a "amigação" adotada pelo sertanejo o desvio da moralidade. A norma só se pode concretizar quando o padre consegue reunir vários casais que vivem matrimonialmente juntos sem a benção e realizar o casamento de cordão ${ }^{5}$. Entretanto, mesmo o padre tentando fazer valer a norma, ainda, existia um pequeno grupo, os "mambembes" que não se preocupam com este contrato matrimonial de modo que "juntam-se por aí, como brutos. E casam-se depois no cordão, se se casam” (RAMOS, 1941, p. 222).

Raul Antelo aponta que o cronista retrata uma sociedade antiquada que insiste em uma relação bem delimitada entre "o proprietário e o mambembe, o forte e o fraco", segundo os moldes tradicionalistas do interior nordestino:

Assim como a sociedade é interpretada sob o prisma do dualismo quase feudal, as relações entre as pessoas, os papéis que elas desempenham, sofrem um esquematismo correlato. Existe o proprietário e o mambembe, o forte e o fraco, o homem e a mulher; contudo a posição do narrador não é nenhuma e

\footnotetext{
${ }^{3} \mathrm{O}$ uso do presente do indicativo para descrever fatos ocorridos no passado é o chamado presente histórico ou narrativo. Trata-se de um recurso utilizado para dar mais vivacidade ao texto e realçar os acontecimentos que estão sendo descritos.

${ }^{4}$ Apesar de o Estado Novo ter sido instaurado apenas em 1937, considera-se como marco fundador da política de Vargas a revolução de 1930.

${ }^{5} \mathrm{Na}$ mesma crônica, o cronista relata como é realizado o procedimento do casamento de corda no interior nordestino: "Alinha-se grande número de infratores junto a um barbante estendido e, em dez minutos, numa única operação, todos se sacramentam”. (RAMOS, Graciliano. Quadros e costumes do nordeste. Cultura Política. Rio de Janeiro, ano 1, n.4, jun. 1941, p. 222).
} 
nem outra - simpatiza com os fracos, mas pertence ao mundo dos proprietários. Daí uma posição intersticial, ambígua, instável, que se constrói apelando, alternativamente, a traços de ambos os grupos (ANTELO, 1984, p. $34)$.

Portanto, o narrador ficou incumbido de nos mostrar a oscilação entre o forte e o fraco de modo que, se simpatiza com os fracos, entretanto, pertence ao mundo dos proprietários.

Diferentemente, das crônicas I e VII, o cronista não teve a preocupação em situar os fatos no passado em relação à contemporaneidade do leitor, inclusive utilizou verbos no presente ${ }^{6}$. Tal indicação se dá pelo fato de não haver uma preocupação por parte do colaborador em equilibrar as palavras, pois não foram abordados temas que pudessem fazer oposição direta ou indiretamente aos pressupostos da revista, uma vez que Graciliano mencionou o tema do casamento, uma tradição que atingia os interioranos nordestinos, podendo ser contemporânea ou não à publicação do periódico. Logo, retratar os costumes e a tradição do sertanejo em relação ao casamento era demonstrar para a sociedade litorânea o conservadorismo e a cultura do homem do sertão.

Outra crônica que fez uso do presente, e situou os fatos na atualidade da publicação em Cultura Politica, foi a crônica XVIII, intitulada em Viventes das Alagoas como "Transação de Cigano". Neste escrito o cronista nos mostrou a estrutura econômica predominante no sertão nordestino em que, segundo ele, havia os que dominavam e os que eram dominados. Esse consentimento, que aconteceu por causa da estrutura social e cultural da região, nos leva a perceber que o sertanejo se acomodou e aceitou os preceitos da lei do mais fraco e do mais forte, que predominava em sua sociedade, pois para ele "Quem é do chão não se trepa. Quem nasceu para vintém não chega a tostão" (RAMOS, 1942, p. 311).

Assim, podemos entender que o intuito do cronista era mostrar com criticidade a acomodação cultural do homem sertanejo, que se convencia de sua fraqueza e aceitava a ordem social imposta por aqueles tidos como espertos e malandros, pois "quer estejamos de acordo quer não estejamos, a operação dolorosa tem de realizar-se, porque isto é a vontade de Deus" (RAMOS, 1942, p. 311).

A crônica XI, intitulada em Viventes das Alagoas como Libório, também, retratou os costumes adotados pelo típico malandro da região nordestina. Esta crônica, assim como a I, contou com a nota do editor, que estabeleceu uma série de suposições com o intuito de

\footnotetext{
${ }^{6}$ Em apenas duas crônicas Graciliano Ramos utilizou os verbos no presente, simbolizando contemporaneidade dos fatos com a época de publicação.
} 
direcionar a leitura.

\section{Uuadros e costumes do Nordeste}

\section{$\mathrm{XI}$}

\section{GRAGILIANO RAMUS}

O tema do frestente artigo é a retrataçüo de un tipo lendario on mesmó verldicu to malandro nordestino. $O$ autor conta tuma historia, naturalmente passada realmente, de um certo Liborio, que a tradiš̃o oral ronser. ta nos seits poulos mais sugestivos.

O Liborio faz tma certa Jalcatrua que envolve am vigario. falcatrua essa de espertalialo. mas o fuiroco näo se deixou enganar, ficando nume situaşäo melindrosa. Por fim o riborio passa o "conto" noutro maluto, contimuando a fazer stas stias.

Nota do editor da crônica XI (ano 2, n. 11, jan. 1942)

Podemos perceber que o editor na nota utilizou o termo artigo para fazer referência à crônica XI, escrita por Graciliano Ramos, para retratar a personagem lendária Libório. Tal fato aconteceu porque não houve uma preocupação do editor com a distinção entre os conceitos de crônica e artigo, pois sua atenção estava esclusivamente relacionada à proposta estabelecida pela orientação da revista, e sua pretenção era apenas direcionar a leitura da crônica de Graciliano Ramos, inferindo em sua interpretação.

A nota do editor evidenciou que Libório foi uma personagem lendária verídica. Contudo, na crônica o escritor deixou claro que o malandro nunca existiu. "Esta façanha pode ser atribuída a Libório, personagem curiosa que provavelmente nunca existiu. E que, sem ter existido, viajou muitos anos pelo Nordeste, realizando falcatruas com engenho, de sorte que as vítimas ficavam sempre em situação ridícula" (RAMOS, 1942, p. 249).

$\mathrm{O}$ intuito da nota do editor era tornar Libório uma personagem real e histórica que viveu no sertão abandonado antes de 1930 e, coerentemente, afirmar que os mais espertos encontravam a melhor maneira de sobreviver naquele espaço. Entretanto, Graciliano no início da crônica ficcionalizou e destacou que a permanência da história de Libório nos redutos locais aconteceu por causa da literatura oral e a tradição do contar "causos", recurso típico da região nordestina. Segundo Ramos (1942, p. 249) "as malandragens desse herói, produto da ficção popular e cabocla, provocam simpatia e riso".

Portanto, o malandro sabia que vivia em um sertão bárbaro que considerava o 
assassinato um crime menor do que o roubo e a trapaça, mas mesmo assim resolveu enganar o padre local. Para tal proeza foi ao confessionário e depois de dois meses voltou afirmando que tinha entregado uma quantia em dinheiro ao vigário que assustado negou aos berros que havia pegado o dinheiro. O malandro espertamente ficou calmo e diante da atitude a população ficou dividida. Todavia, um esperto que observava a cena resolveu armar uma cilada para Libório de modo que este entrasse em contradição. O homem disse que o dinheiroestava com ele e esperava que Libório se assutasse e entregasse a armação, contudo, o malandro sabiamente afirmou que buscaria o dinheiro que estava de posse do esperto, mas que naquele momento estava ali para receber o que havia entregado ao padre. "Agora quero receber o que entreguei a seu vigário. Dê cá o meu conto de réis, seu vigário, tenha paciência. Faça como o seu amigo, que deve e confessa diante do povo, não esfola os pobres" (RAMOS, 1942, p. 249).

Assim, quando Libório conseguiu enganar o nativo esperto se tornou o herói das trapaças e das malandragens. Nesta crônica XI, a estratégia da revista foi a nota do editor que tentou desficcionalizar a história de Libório, dando uma interpretação verídica às trapaças do malandro em um passado não identificado, com a tentativa de afirmar que estas trapaças realmente existiram, mas que ficaram para trás, distantes da política do Estado Novo. A estratégia utilizada por Graciliano Ramos, por sua vez, foi ficcionalizar as ações de Libório e reportar as trapaças do malandro em um passado distante sem citar em momento algum a política implantada por Getúlio Vargas.

Também Ciríaco ${ }^{7}$, personagem principal da crônica $\mathrm{V}$, pode ser considerado como um exemplo da cultura, da sociedade e da esperteza local nordestina. Trata-se de um caboclo forte que trabalhava em uma fazenda no interior de Pernambuco, conhecido por todos apenas pelo primeiro nome.

O sertanejo, conhecedor invejável dos bois e da cultura local, dividia a sua morada com o narrador da crônica, um jovem que tinha os seus costumes e hábitos marcados pela regra e pela leitura, ao contrário de Ciríaco, que possuía uma linguagem gutural e um vocabulário pequeno. Logo, para Ramos (1941, p. 242): "Dispunha de vocabulário escasso e falava aos arrancos, misturando assuntos, deixando as frases incompletas, entre silêncios".

\footnotetext{
${ }^{7} \mathrm{O}$ nome da personagem Ciríaco adveio de passagens memorialísticas, uma vez que um dos funcionários da fazenda de seus familiares no interior do Pernambuco se chamava Ciríaco. Esta informação pode ser comprovada no livro de memórias Infância e na obra póstuma Cartas.
} 
Diferentemente de Fabiano $^{8}$, personagem de Vidas Secas que também emitia sons guturais, Ciríaco, apesar de possuir um vocabulário escasso, conseguia seduzir a todos de sua região com suas histórias, sendo considerado no local como uma espécie de herói popular.

A crônica XVI nos apresentou, também, como personagem central o gramático da região, um ser que, apesar de buscar instruções nos livros e nas gramáticas, ainda fazia questão de valorizar a cultura e a fala local de seu povo, pois para ele a preservação da cultura e da tradição eram elementos essenciais na sua formação. O gramático valorizava as particularidades da sua fala, dos seus costumes, das suas crenças e do seu folclore. O cronista deixou claro que o homem sertanejo preservava a sua comunicação por meio da tradição.

Em um dos trechos da crônica, Ciríaco, preservando a fala local, conversou com o narrador e o questionou sobre a origem do mundo. Com calma e sabedoria escutou e somente no final emitiu o seu parecer: "Pensa que eu acredito nestas besteiras" (RAMOS, 1941, p. 242). Diante de tal resposta de Ciríaco, podemos perceber que o cronista, por meio da opinião da personagem, nos mostrou o olhar desconfiado do homem do sertão em relação aos ensinamentos advindos da cultura urbana.

Como a maioria das colaborações de Graciliano em Cultura Política, a crônica V apresentou os fatos da cultura e da sociedade nordestina em um passado distante, inclusive, em alguns momentos, temos passagens memorialísticas que lembram a infância de Graciliano, na fazenda da família em Pernambuco 9 .

Quando Graciliano colocou em cena a cultura nordestina, seja ela vista de maneira atrasada ou valorizada, de certa forma, atendeu a um dos principais requisitos proferidos por Almir de Andrade em Cultura Política. Noutras palavras, segundo o editor da revista, era preciso despertar, reforçar e aumentar a consciência política juntamente com a cultura do país. Nesse sentido, para Almir de Andrade (1941, p. 07) os seus colaboradores deviam procurar "espelhar o Brasil sob tôdas as suas faces - sociais, intelectuais e artísticas" com o objetivo de testemunhar que esta consciência estava surgindo com o Estado Novo, "como resultante da evolução da nossa mentalidade social".

\footnotetext{
${ }^{8}$ Assim como Ciríaco, a personagem Fabiano de Vidas Secas, também, possuía uma linguagem escassa e gutural. Em uma das passagens de Vidas Secas, o narrador no capítulo Fabiano tece o seguinte comentário sobre a personagem: "Vivia longe dos homens, só se dava bem com os animais. Os seus pés duros quebravam espinhos e não sentiam e quentura da terra. Montado, confundia-se com o cavalo, grudava-se a ele. E falava uma linguagem cantada, monossilábica e gutural, que o companheiro entendia. [...]” (RAMOS, 1970, p. 19). 9 Para Arriguggi Jr., "lembrar e escrever: trata-se de um relato em permanente relação com o tempo, de onde (o
autor) tira, como memória escrita, sua matéria principal, o que fica do vivido" (ARRIGUCCI JR, 1987, p. 51).
} 
Diante de tal imposição, Graciliano não fez caso, pois acreditava que a cultura da sua terra e os costumes do seu povo deveriam ser mostrados a todos, de modo a inferir que o Nordeste também fazia parte do Brasil e deveria ser tratado como parte integrante do nosso país. Entretanto, em nenhum trecho da crônica, o escritor evidenciou que o Estado Novo era o responsável pela evolução da nossa mentalidade social. Podemos perceber, portanto, que havia uma espécie de equilíbrio entre as duas partes: colaborador e periódico.

Desse modo, a partir das observações e reflexões é interessante apresentar de forma gráfica a seleção e a classificação das crônicas que se encontram em Cultura Política, de acordo com o tema predominante usos e costumes da sociedade:

\begin{tabular}{|c|c|c|c|c|}
\hline Seção & $\begin{array}{l}\text { Título em } \\
\text { Cultura } \\
\text { Política }\end{array}$ & $\begin{array}{l}\text { Título em } \\
\text { Viventes das } \\
\text { Alagoas }\end{array}$ & Espaço & Tempo \\
\hline $\begin{array}{l}\text { Quadros e Costumes } \\
\text { do Nordeste }\end{array}$ & I & Carnaval & $\begin{array}{l}\text { Cidadezinha } \\
\text { sertaneja }\end{array}$ & Antes de 1930 \\
\hline $\begin{array}{l}\text { Quadros e Costumes do } \\
\text { Nordeste }\end{array}$ & IV & Casamento & $\begin{array}{l}\text { Interior do } \\
\text { Nordeste }\end{array}$ & $\begin{array}{l}\text { Contemporâneo à } \\
\text { publicação - } \\
\text { Presente }\end{array}$ \\
\hline $\begin{array}{l}\text { Quadros e costumes do } \\
\text { Nordeste }\end{array}$ & $\mathrm{V}$ & Ciríaco & $\begin{array}{l}\text { Fazenda do } \\
\text { interior de } \\
\text { Pernambuco }\end{array}$ & $\begin{array}{l}\text { Antes de } 1930 \\
\text { (menção a dados } \\
\text { biográficos ao início } \\
\text { do século XX) }\end{array}$ \\
\hline $\begin{array}{l}\text { Quadros e Costumes do } \\
\text { Nordeste }\end{array}$ & VI & Habitação & $\begin{array}{l}\text { Sertão } \\
\text { Nordestino }\end{array}$ & $\begin{array}{l}\text { Antes de } 1930 \text { (menção } \\
\text { a dados biográficos } \\
\text { referentes ao início do } \\
\text { século XX) }\end{array}$ \\
\hline $\begin{array}{l}\text { Quadros e Costumes do } \\
\text { Nordeste }\end{array}$ & VI & Habitação & $\begin{array}{l}\text { Sertão } \\
\text { Nordestino }\end{array}$ & $\begin{array}{l}\text { Antes de } 1930 \text { (menção } \\
\text { a dados biográficos } \\
\text { referentes ao início do } \\
\text { século XX) }\end{array}$ \\
\hline $\begin{array}{l}\text { Quadros e costumes } \\
\text { do Nordeste }\end{array}$ & VII & Teatro I & Capital & $\begin{array}{l}\text { Primeira década do } \\
\text { século XX }\end{array}$ \\
\hline $\begin{array}{l}\text { Quadros e costumes do } \\
\text { Nordeste }\end{array}$ & VIII & Teatro II & $\begin{array}{l}\text { Cidadezinha } \\
\text { sertaneja }\end{array}$ & $\begin{array}{l}\text { Entre o final do século } \\
\text { XIX e as primeiras } \\
\text { décadas do } \\
\text { século XX }\end{array}$ \\
\hline $\begin{array}{l}\text { Quadros e Costumes } \\
\text { do Nordeste }\end{array}$ & XI & Libório & $\begin{array}{l}\text { Cidadezinha } \\
\text { sertaneja }\end{array}$ & $\begin{array}{l}\text { Passsado não } \\
\text { Identificado }\end{array}$ \\
\hline $\begin{array}{l}\text { Quadros e Costumes do } \\
\text { Nordeste }\end{array}$ & $\mathrm{XVI}$ & Um gramático & $\begin{array}{ll}\text { Patos, } & \text { no } \\
\text { estado } & \text { da } \\
\text { Paraíba. } & \\
\end{array}$ & Por volta de 1930 \\
\hline
\end{tabular}




\begin{tabular}{|c|c|c|c|c|}
\hline $\begin{array}{l}\text { Quadros e costumes do } \\
\text { Nordeste }\end{array}$ & XVII & Dr. Pelado & $\begin{array}{l}\text { Cidade do } \\
\text { interior e } \\
\text { Sertão }\end{array}$ & Começo do século \\
\hline $\begin{array}{l}\text { Quadros e costumes do } \\
\text { Nordeste }\end{array}$ & XVIII & $\begin{array}{l}\text { Transação de } \\
\text { cigano }\end{array}$ & $\begin{array}{l}\text { Sertão } \\
\text { Nordestino ( } \\
\text { referência } \\
\text { indireta). }\end{array}$ & \begin{tabular}{|lr} 
Presente & - \\
contemporâneo & à \\
publicação & da \\
crõnicam & Cultura \\
Política. & \\
\end{tabular} \\
\hline $\begin{array}{l}\text { Quadros e costumes } \\
\text { regionais }\end{array}$ & $\begin{array}{l}\text { "Está aberta a } \\
\text { sessão do juri' }\end{array}$ & 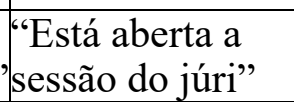 & $\begin{array}{l}\text { Cidadezinha } \\
\text { sertaneja }\end{array}$ & \begin{tabular}{|l} 
Passado \\
identificado
\end{tabular} \\
\hline
\end{tabular}

Tabela elaborada pela autora. Crônicas de Cultura Política: Usos e costumes da sociedade.

Assim, ao analisar estas crônicas revestidas de ficção, que abordaram como tema central a sociedade e a cultura nordestina, percebemos a presença de um narrador responsável por relatar os costumes de uma sociedade que não pertencia mais ao mundo em que o cronista vivia; em outros termos, ele apenas recordava os acontecimentos e os imprimia em Cultura Política para leitores intelectualizados dos grandes centros do sul e do sudeste, com o intuito de mostrar como o homem nordestino se comportava, principalmente, antes de 1930.

Outro ponto que não podemos deixar de destacar é que, em momento algum, o cronista fez menção honrosa ou criticou Getúlio Vargas, tanto que nem sequer citou o nome do presidente em suas colaborações. O cronista, nesse sentido, contou com a perspicácia do leitor para decifrar que, em muitos momentos, suas colocações apresentaram fatos que pertenciam tanto ao passado, antes de 1930, quanto ao momento contemporâneo de suas publicações.

Nesse sentido, quando colocou os fatos, em sua maioria, no passado ou no presente histórico, levou o leitor, num primeiro momento, a pensar que as peculiaridades sociais e culturais faziam parte de um nordeste que ficou na Primeira República. Entretanto, podemos dizer que em 1930 houve uma mudança de governo e não uma transformação radical que alterasse o Brasil da noite para o dia, principalmente nas regiões mais afastadas do eixo centrosul.

Podemos concluir que em Cultura Política, o cronista fez considerações sobre a forma de governar, de fazer transações econômicas, sobre os usos e costumes e na linguagem da região nordestina, principalmente durante o período da Primeira República, sem, contudo, desvalorizar a região ou esquecer que situações semelhantes poderiam acontecer também no restante do Brasil. O cronista, não praticou, em momento algum, a generalização destes fatos e muito menos citou o nome dos governadores, apenas mencionou de forma indireta os acontecimentos que induzem o leitor a pensar e a refletir sobre os procedimentos adotados em um período 
anterior e, até mesmo, contemporâneo à publicação da revista.

\section{REFERÊNCIAS}

ANDRADE, Almir de. Política e Cultura. Cultura Política, Rio de Janeiro, ano 1, n. 2, abr. 1941, p.7.

ANDRADE, Almir de. Quadros e costumes do nordeste. Cultura Politica. Rio de Janeiro, ano1, n. 1, mar. 1941, p. 236.

ANTELO, Raul. Literatura em Revista. São Paulo: Ática, 1984.

ARRIGUCCI JR, Davi. Enigma e comentário: ensaios sobre literatura e experiência. São Paulo: Companhia das Letras, 1987, p. 51).

Cultura Política. Rio de Janeiro: Departamento de Imprensa e Propaganda. 1941-1945.

Mensal. Disponível em: 〈http://www.cpdoc.fgv.br/nav_historia/htm/anos37-45> Acesso: 18 jun. 2019.

CANDIDO, Antonio. Prefácio. In: MICELI, Sergio. Intelectuais à brasileira. São Paulo: Companhia das Letras, 2001.

COUTINHO, Afrânio. Ensaio e crônica. In: COUTINHO, Afrânio (Dir.), COUTINHO, Eduardo de Faria (co-dir.). A literatura no Brasil. 4. ed. rev. e at. São Paulo: Global, 1997.

PETERLE, Patricia. Ignazio Silone e Graciliano Ramos, um olhar dialógico. In: PETERLE, Patricia (Org). Ignazio Silone: ontem e hoje. Rio de Janeiro. Editora Comunità, 2010, 74p.

RAMOS, Graciliano. Quadros e costumes do nordeste. Cultura Política. Rio de Janeiro, ano 1, n. 1, mar. 1941, p. 236-237.

RAMOS, Graciliano. Quadros e costumes do nordeste. Cultura Política. Rio de Janeiro, ano 2, n. 11, jan., 1942, p. 249.

RAMOS, Graciliano. Quadros e costumes do nordeste. Cultura Política. Rio de Janeiro, ano 1, n. 4, jun. 1941, p. 222.

RAMOS, Graciliano. Quadros e costumes do nordeste. Cultura Política. Rio de Janeiro, ano 1, n. 5, jul. 1941, p. 242.

RAMOS, Graciliano. Quadros e costumes do nordeste. Cultura Política. Rio de Janeiro, ano 1, n. 7, set. 1941, p. 263.

RAMOS, Graciliano. Quadros e costumes do nordeste. Cultura Política. Rio de Janeiro, ano 2, n. 11, jan. 1942, p. 249.

RAMOS, Graciliano. Quadros e costumes do nordeste. Cultura Política. Rio de Janeiro, ano 2, n. 18, ago. 1942, p.311

RAMOS, Graciliano. Vidas Secas. São Paulo: Martins,1970. 